\title{
Institutional management of peer-led learning: a framework for holistic integration
}

Jason Eyre

De Montfort University, Leicester, UK

\section{Abstract}

If we are to accept that peer-led learning (peer mentoring, peer tutoring and related approaches) are of benefit to students, how are we to approach the implementation of such approaches at the institutional level in a way that is resource efficient and effective? This paper presents the holistic framework for the institution-wide coordination and support of a wide variety of peer-led learning initiatives developed at De Montfort University. The framework presented sidesteps the thorny issues of categorisation that dominate the discourse of peer-led learning by devolving issues of definition to the site of implementation. A simplified typology is presented that characterises an initiative based on its level of formality and its overarching purpose with respect to transformational 'transition points' through the student lifecycle. This 'mixed economy' approach accommodates highly idiosyncratic and locally-defined approaches to peer-led learning coordinated and supported by the university's learning development unit (the Centre for Learning and Study Support).

Keywords: peer-led learning; peer mentoring; institutional management (higher education); disciplinarity.

\section{Introduction}

Peer-led learning (incorporating peer mentoring, peer assessment, peer tutoring and other forms of student-to-student learning activity) is becoming ubiquitous in UK higher education as approaches to enhancing student learning, with numerous studies and reports attesting to their efficacy (e.g. Andrews and Clark, 2011; Andreanoff, 2013; Fox 
and Stevenson, 2006; Dawson et al., 2014; Keenan, 2014). The purpose of this paper is not to add to the burgeoning literature with another case study, but rather to consider the following question: if we accept that peer-led learning can be of benefit to university students, how are we to approach its implementation from an institutional perspective? This is a question of particular relevance to institutional managers, Learning Developers, Educational Developers and others concerned primarily with providing coordination and support across a wide range of courses and programmes in a resource-efficient way.

Building on the work of Jacobi (1991), which reviewed the literature on mentoring and undergraduate academic success in the United States from the 1970s to the late 1980s, two more recent papers by Crisp and Cruz (2008) and Gershenfeld (2014) reviewed 62 empirical and theoretical studies between them on mentoring in a higher education setting between 1990-2012, including a number of international (non-US) studies. While many of the studies reviewed looked at mentoring more broadly (often between a faculty member and a student), it is clear that peer mentoring (mentoring between students) has become increasingly prevalent. A common theme across all three review papers is the absence of a clear definition of 'mentoring' (Crisp and Cruz found over 50 definitions - in a review of 42 studies). Combined with a lack of a coherent underpinning theory, the concern of these researchers is that the potential benefits of mentoring for undergraduate students cannot be fully realised until there is some degree of clarity as to what we actually mean by it.

It is apparent from a number of the papers reviewed by these authors that some of the activities described more closely resemble 'peer learning' or 'peer tutoring' than they do mentoring (terms are often used interchangeably, which is part of the problem). Definitions of course vary greatly but, generally speaking, 'peer tutoring' (or 'peer learning') tends to focus on discipline-based content knowledge and skills, while 'peer mentoring' focuses more on personal development (settling in, approaches to study, and so on). At best the boundaries between the two concepts are blurred. Topping and Ehly (1998, p.9) are adamant that peer tutoring and peer mentoring 'are not to be confused with one another', while Falchikov (2001) is more ambivalent, seeing mentoring as complementary to peer tutoring. Andrews and Clark's 2011 HEFCE/HEA report 'Peer Mentoring Works!', which takes peer mentoring in higher education as its clear focus, recognise this ambiguity. The approach to peer mentoring that the report's authors advocate is effectively a synthesis of elements of peer mentoring and peer tutoring. The numerous approaches based on the proprietary Supplemental Instruction model (PASS, PAL) tend to focus primarily on the 
tutoring aspect, although there are elements of mentoring in some initiatives (Keenan, 2014). As Andrews and Clark (2011) recognise, the difficulty lies in where more general support ends and academic support begins. This paper will use the collective term 'Peerled learning' employed by Keenan (2014) unless referring to one or another manifestation.

This apparent confusion of terminology and approaches represents a potential barrier to the coherent and systematic implementation of peer mentoring and/or peer learning at the institutional level: it may be unclear which of the myriad definitions is appropriate to a given institutional setting, and which of the evidence to be found in the published literature can therefore be appropriately applied. It is consequently unclear which approach or approaches to peer mentoring or peer learning ought to be pursued, an issue compounded by the sheer number of apparently synonymous terms (buddying, coaching, guiding etc., see Andrews and Clark, 2011, p.16) and a range of competing taxonomies and frameworks (e.g. Terrion and Leonard, 2007; Falchikov, 2001). Much of the literature is concerned with untangling these knots in order to gain some sort of clarity.

The approach outlined in the present paper sidesteps this conundrum. Rather than attempting to clarify the definitions and appraise the competing theories, this paper will instead argue that being definitive in this way is not necessary in order to effectively coordinate and support peer mentoring and peer learning at an institutional level. This does not mean we ought to be resigned to a piecemeal, ad hoc approach characterised by a panoply of disconnected initiatives and schemes. It is possible to have a coordinated approach to peer-led learning that leaves the problems of definition to those who are running the schemes at a local level. For the academics based in particular subject disciplines, it is only necessary to define their own particular approach to peer-led learning, and in so doing the issue of definition instead becomes one of specific application. Although not without its own challenges, this leaves the task of coordination and support to stand outside and alongside individual initiatives, with the potential to allow diversity and innovation to flourish. Such is the nature of the 'mixed economy' approach developed at De Montfort University to be outlined below.

The present paper represents a reflexive account of the development of peer-led learning at one British university. The particular circumstances that have led to this development may of course not be applicable to all higher education institutions. However, given the burgeoning popularity of peer-led learning in higher education, the framework presented 
here should at least foster debate and critical reflection on how peer-led learning could be considered holistically at the institutional level. A short précis of the development of peerled learning will be sketched in the first part of this paper to provide the necessary contextual background. This will be followed by the presentation of a functional typology of peer-led learning developed through an analysis of the diverse offerings that have emerged across the institution. The final section presents a brief discussion of the resulting institutional framework and the role of Learning Developers in developing and supporting it.

\section{Historical development of peer mentoring and peer learning at De Montfort University}

In order to understand and appreciate the approach to peer-led learning that De Montfort University has taken, it is instructive to first outline the way that it has developed.

Formal institution-wide support for peer-led learning commenced in the 2007/8 academic session when the Centre for Learning and Study Support (CLaSS), De Montfort's centre for Learning Development, organised a series of pilot projects across four subject areas. Each peer mentoring initiative in this pilot phase was different in format and focus, reflecting the different discipline-professional requirements and the particular programme needs of each course of study (see for example Buckingham and Newsham, 2012).

From 2008 to 2012, the number of new peer mentoring schemes supported by CLaSS increased steadily. By 2012 it was recognised that the number of active schemes had appeared to plateau, so new impetus was put into advocacy work. This took the form of both 'bottom-up' and 'top-down' approaches, each complementing the other. The former derived primarily from the testimonials of students themselves alongside those academics and programme leaders who have implemented a successful scheme. Much of this form of advocacy was informal and word-of-mouth, and while slow and incremental, represented an authentic voice with a great deal of credibility. The top-down approach derived primarily from the orchestrated advocacy undertaken by CLaSS itself, presenting to various committees and forums across the university on the potential benefits of peer mentoring. $A$ range of university committees (often attended by quite senior managers) and working groups relating to retention, teaching and learning, and subject-specific pedagogic 
development, were all approached with a view to raising the profile of 'peer mentoring'. Through both bottom-up and top-down advocacy, the profile of peer mentoring was raised considerably, culminating in a university-wide symposium on peer mentoring in 2013.

This raised profile enabled peer mentoring to be 'mainstreamed' and integrated into a range of university-wide agendas ranging from initiatives by the Student's Union, the Quality Enhancement and Improvement Committee, and working groups focused on student retention and student diversity. 'Peer mentoring champions' were appointed in each faculty in order to oversee development more locally (a recommendation from the Student's Union). Peer mentoring, in this light, became recognised as a form of 'good pedagogic practice', and something that ought to be available to all students. This was articulated as the 'parity issue' - if peer mentoring is a good thing, why is it not open and available to all students who want to engage with it?). Concerns over the 'parity issue' led directly to CLaSS successfully advocating for the funding of a 'catch all' scheme (run by the Student's Union) to cater for students whose programme of study did not currently offer an opportunity to engage in peer mentoring.

Peer mentoring's rise to prominence also led to the 'discovery' of a range of peer mentoring and mentoring-related activities in areas that were hitherto unknown to CLaSS or our associated network of peer mentoring enthusiasts. The more we looked, the more we found out about schemes and initiatives that had arisen independently of any input from CLaSS, typically at programme level, and which ranged from buddy schemes to forms of peer assessment. This process of discovery was significantly aided by the facultybased 'peer mentoring champions' through their engagement with local faculty networks, and the mapping of such activity is seen as an ongoing task as initiatives are prone to arise spontaneously. The range of activities broadly labelled 'peer mentoring' were clearly more diverse in their focus than the label suggested. In consultation with our network of academic champions and enthusiasts, CLaSS opted to take a broad view of peer mentoring and peer learning which led directly to the development of the peer-led learning typology outlined in the following section. The term 'mixed economy' began to be used as a way to articulate the diverse approaches being taken in different subject areas.

In addition to programme-based peer-led learning activities, a number of centrally-based schemes were added to the overall institutional picture (for example: employability mentoring; a scheme for international students; faculty-level schemes around work-based 
learning). Considered together, this array of peer-led learning activities resulted in a significant increase in known initiatives, from the four peer mentoring schemes initiated in the 2007/8 pilots to over 30 active and proposed peer-led learning initiatives in 2014/15.

The foregoing sketch traces how a series of self-contained pilots has expanded in scope to form a pedagogic approach that is now being applied across the whole university. It shows that in addition to the centrally-led advocacy for peer-led learning, it is just as likely to grow independently out of a programme of study on the back of the initiative and enthusiasm of academic colleagues. It also demonstrates that each and every instance of peer-led learning is different, based on the particular needs and requirements of the discipline or course of study.

\section{A typology of peer mentoring and peer learning}

The historical development of peer-led learning at De Montfort University presented in the previous section documented what can appear at face value to represent a rather haphazard and piecemeal approach to its management and coordination. After all, peerled learning was not planned and implemented at De Montfort from the top down; rather, it has evolved organically over a period of many years - from the ground up, as well as in a semi-coordinated fashion. But this organic origin should not be confused with a chaotic state of affairs, and the purpose of what follows is to set out De Montfort's approach to peer-led learning in a more systematic fashion.

\section{A diversity of needs leads to a diversity of approaches}

From the outset, the ethos of the pilot projects was based on the principle that each initiative would be 'discipline-owned, student led, and supported by CLaSS'. This formulation set the tone of the pilots and the initiatives that followed. It was made clear to colleagues early on that CLaSS was not in a position to run any of the schemes on a dayto-day basis. That responsibility must rest with the programme and its students, based on principles of localism and volunteerism. What is best for the programme is best determined by the programme itself (that is, co-created by academics and students alike), and not determined centrally and imposed upon them from without; and furthermore, any such initiative would only be effective if it was voluntary rather than compulsory. Once a 
scheme was in place, CLaSS would step back and allow the programme to run the scheme, academics and students in partnership, with support provided from CLaSS whenever it was sought.

As a result, no two peer-led learning initiatives are exactly alike. There is consequently no benefit in seeking to clearly define what constitutes 'best practice' in peer led-learning with a view to implementing that singular approach across all courses; 'good practice', on the other hand, could be collated and shared. A 'discipline-owned, student led' foundation means that a principle of localism prevails, with each programme/discipline setting out what it feels to be the appropriate focus and level of formality for its own students. Once implemented, there is no reason why this cannot also undergo change as the needs of the programme and its students change.

\section{Transition points}

While the needs of different programmes represent a colourful array of possibilities, they can all be seen as constituting definable 'transition points' for their students. Following Hilsdon's (2013) formulation of peer learning and identity, peer-led learning can be conceptualised as a series of shifting identifications, the transition into each of which can conceivably be supported by those who have recently undergone similar transitions in a similar context. In a UK higher education setting, such transition points may include the following:

- Transition to the UK.

- Transition into university-level study.

- Transition into the institution itself.

- Transition to independent living.

- Transition into a particular course of study.

- Transition to higher academic expectations (e.g. into year 2 of an undergraduate course).

- Transition to new embodied practices (e.g. lab or studio work).

- Transition to independent researching (e.g. towards the end of year 2.

- Transition to placement practice.

- Transition into a professional identity. 
- Transition out into the professions.

- Transition into uncertain employability.

- Transition into entrepreneurship.

This is by no means an exhaustive list and represents a broadening out of traditional views of 'transitions' when applied to peer mentoring and peer-led learning. In seeking to find a focus for a new initiative, CLaSS will work with academic colleagues to consider which transition points are most salient to their students, and these form the basis for any discussions that follow in terms of the composition and logistics of the resulting scheme.

\section{Formality and focus}

Given the diversity of need for peer-led learning activities, and given the range of potential focal points within a particular scheme, it is unsurprising that rigid definitions of 'peer learning' or 'peer mentoring' fail to capture the sheer diversity of what happens on the ground. It is our view that attempting to define schemes in these terms may provide muchneeded clarity for some, but ultimately is not necessary in terms of providing support and building a network of practitioners.

Instead, we contend that all peer-led learning activities can be plotted as a 'typology' along two axes that represent the informality/formality of a scheme along one continuum, and the area of focus from the pastoral/social through the academic and professional domains of transition on the other (see Figure 1).

Informal approaches are those that are undertaken with a minimal level of control over the activities that students undertake. At one extreme, 'mentors' are not trained (and could not realistically be considered 'mentors'), participants are not selected or registered, and little or no attempt is made to evaluate the success or otherwise of the endeavour. Consequently, informal approaches tend to have fewer costs attached to them. Formal approaches, by contrast, are more rigidly controlled, with selection, training, monitoring and evaluation during and after a scheme's operation. These approaches are naturally more resource-intensive.

On the other axis, pastoral/social focused activities comprise one end of the scale - peerled learning that revolves around aspects of socialisation and integration such as that 
which takes place in 'buddy' schemes focused on inward transitions to study; at the other end of the scale the focus is on academic work, and traditional forms of peer learning and Supplemental Instruction lie at this end of the spectrum. Professional/discipline identity forms an interesting category that doesn't neatly fit into such a simplified typology and which could in fact be given equal expression at either the socialisation end of the spectrum (introducing professional values in the first year of study) or the academic end (application of specialist professional knowledge), depending on the degree of complexity of the knowledge. As developed, the typology typically places the professional alongside the academic as specialist 'content' knowledge that requires input (and supervision) from academic staff or highly experienced students in order to be properly conveyed.

\section{Figure 1. Peer-led learning typology.}

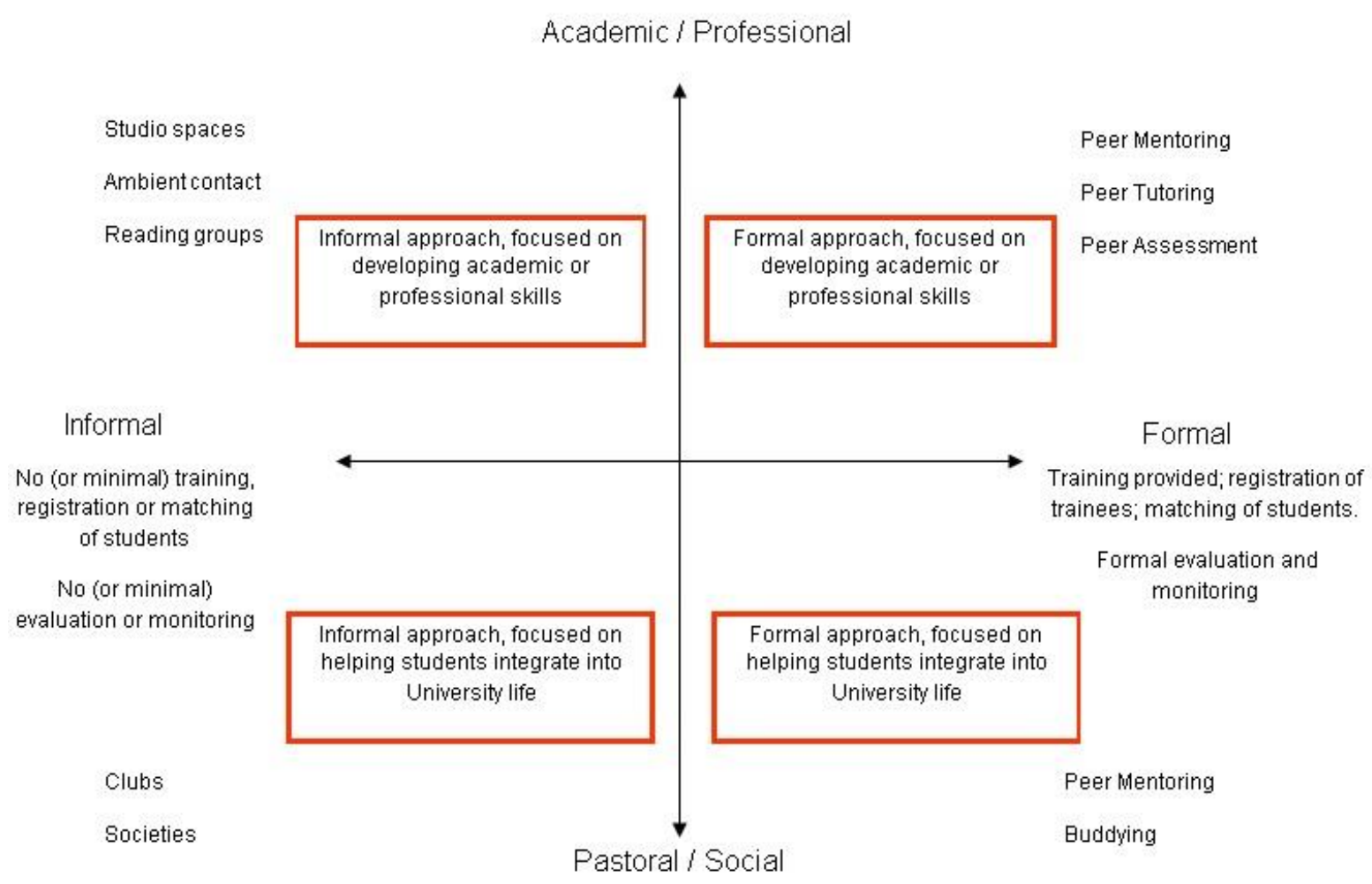

Putting the two axes together produces four quadrants. In the top right sits the formalacademic/professional quadrant, home to formalised peer learning (including peer tutoring and peer assessment) and some forms of peer mentoring where academic and professional activities are engaged with by the mentor/mentee. At the bottom right sits the formal-pastoral/social quadrant where various 'buddy' schemes and inward-transition initiatives are clustered, along with other forms of peer mentoring where academic and 
professional issues are considered less important than socialisation and enculturation. Both of these quadrants are associated with a degree of organisation that requires some on-going provision of resources.

In the top left corner lies the informal-academic/professional quadrant. This may at first appear counter-intuitive, as the academic/professional domain has already been characterised as requiring some degree of intercession on behalf of academics - which in turn implies a degree of formality. However, this particular quadrant is where a number of spatially-constructed approaches to peer-led learning can be located, which includes initiatives such as book groups and reading clubs, and even less formalised approaches such as 'peer spaces', which constitutes a recognition of the observation that if you mix students at different year levels in a common space, a degree of informal learning will occur as they intermingle - an insight common to many studio based disciplines and librarians (see Powis, 2010).

The final quadrant at the bottom left is perhaps easily overlooked when considering peer working. This constitutes the informal-pastoral/social quadrant, which at De Montfort includes the various sports clubs, Student Union-led societies, faculty-sponsored clubs, and regular or occasional social events designed to help students integrate into a particular aspect of university life. Granted, many of the clubs and societies will have a formal element (membership registration, for example) and at De Montfort, as at many other universities, a number of the sporting clubs also incorporate semi-formalised mentoring initiatives as well, but the peer working within them will often be a side-line to the group's main activities (such as playing sport), not the primary reason for its inception, hence 'informal' within the scope of the typology.

The informal half of the typology may not represent what many in higher education understand as 'peer-led learning', and it is the case at De Montfort that sporting clubs and union-run student societies, for example, are not 'counted' as peer-led learning initiatives; but they do represent instances where students interact with other students in situations where they are likely to learn things and develop certain skills, competencies and importantly - their confidence, all of which make a broad contribution to their overall academic development. As such, they provide useful polarities against which it is possible to plot the various 'peer' activities on offer across the university. 
Deciding exactly where on the graph a particular peer-to-peer activity sits is not the point, however; the typology has been developed primarily as a tool for communication, to demonstrate that all forms of peer-led learning can be considered holistically and understood in relation to the other forms. In mapping peer-led learning across the institution, such a tool has formed the basis for a shared understanding and allows contested terms such as 'mentoring' and 'tutoring' to be put to one side in order to allow a focus on the practicalities of planning, implementing and evaluating individual initiatives.

\section{Institutional management of peer-led learning}

The array of formal and semi-formal peer-led learning activities undertaken at De Montfort, alongside the many informal offerings (which by definition, are not 'formally' supported by CLaSS), represent what one academic colleague characterised as the 'mixed economy' approach to peer-led learning. As discussed, the primary benefit of this approach is that each individual initiative is closely tailored to the needs of a particular programme of study or subject area, which in turn leads to greater relevance for the students and improved prospects for sustainability and embedding. At De Montfort, these localised or devolved initiatives are supplemented by more universal or centralised ones. The result is an institution-wide framework for peer-led learning (Figure 2). 
Figure 2. Institution-wide framework for peer-led learning at De Montfort University.

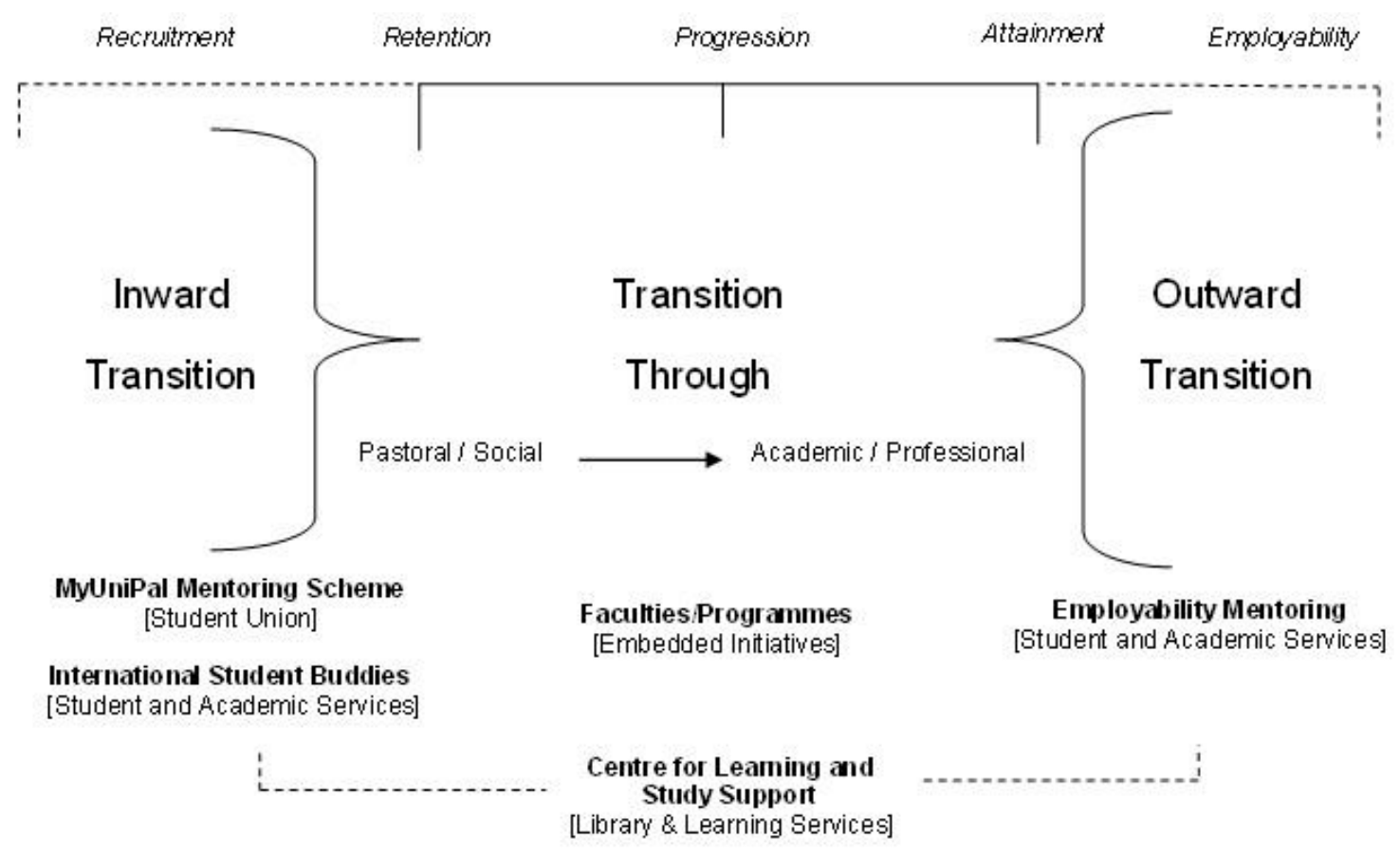

The broadening out of the concept of 'transition' from narrow associations with institutional entry to incorporate transitional transformation throughout the student lifecycle, has ensured that this 'mixed economy' is even more closely aligned with programme and student needs, and not constrained by prescriptive definitions of what constitutes appropriate 'peer mentoring' or 'peer tutoring' activities. It also provides the necessary framework for the scaling-up of peer-led learning initiatives institution-wide.

Given the highly devolved nature of these initiatives, what role, if any, is there for central coordination and support? CLaSS retains its coordinating and supportive function, even as it became clear that not all initiatives across the institution would require direct input from us, and has positioned itself as a hub for peer-led learning activity across the university. Without some kind of information aggregation there is a risk that those involved in supporting isolated initiatives will not be able to benefit from the extensive cross-pollination opportunities that come with being part of a community of interest (Slavin-Baden et al., 2008, p.224). There is a further risk that, left to their own devices, isolated initiatives may flounder when key staff members move on, or may fall short of their potential by not being aware of good practice elsewhere. CLaSS fulfills such a connective function through its advocacy, liaison, and mapping activities, alongside its continued direct input into a number of the more formal schemes (those that occupy the upper right quadrant of our typology). CLaSS are also actively working with colleagues to pilot more academically 
focused peer learning and peer tutoring initiatives where there has been an interest, so those long-standing initiatives are not viewed as static but are continuously evolving.

Furthermore, CLaSS is now able to use this holistic framework to attempt to construct a common approach to the evaluation of peer-led learning initiatives. This sets out a common baseline shared by all initiatives (based on broad values) which then allows the exponents of each initiative to set their own criteria for success within the overarching structure. Each initiative is thereby free to pursue its own distinctive approach, while assuring the wider institution that it is being appropriately appraised in terms of quality. While it is often reported that peer mentoring and peer learning is effective (see Christie, 2014, for a valuable corrective to this apparent orthodoxy), we retain our critical stance and will seek to challenge our academic colleagues to show us how their particular schemes are able to benefit their students. This is done in a spirit of supportive collegiality, hence the insistence that we retain no control over individual schemes, although we are acutely aware of the coercive and surveillance overtones of centralised reporting structures (Ball, 2003). The development of the framework as described, with its underpinning principles of localism and volunteerism, goes a long way to cultivating the trust of our academic colleagues in this respect.

The issue of trust is important here. Tensions between subject disciplines and higher education institutions are widely acknowledged, particularly in the domain of teaching and learning (see Kreber, 2009). In her review of recent literature on peer mentoring, Gershenfeld (2014, p.387) highlights a need for institutional administrators to be aware of the function or role of mentors, and advocates the use of internal data to drive the continuous improvement of operations. While improvement is a worthy aim, the case of De Montfort shows that within a single institution there can be a multitude of different functions and roles for mentors (and roles in student-to-student learning that are distinct from mentoring). A mixed economy does not easily lend itself to a uniform approach to measurement, and any evaluative framework has to be designed in such a way as to take into account the diversity inherent to the system on the one hand, alongside the need of the institution to ensure the ongoing quality of provision overall. There is a risk that in seeking an efficient way to measure effectiveness, an institution may attempt to impose a uniform approach to peer-led learning that is not responsive to local needs and requirements (including a discipline's culture) and which in turn stifles diversity and innovation, and ultimately adversely impacts on the student experience. 
The role of CLaSS, a Learning Development unit, as the central hub of peer-led learning is important in this regard. Learning Developers have long navigated the space between discipline-contextual student learning and its link with strategic-institutional imperatives (see for example Gibson and Myers, 2010). In taking into account both the particular needs of students within their subject disciplines alongside the over-arching role of institutions, Learning Developers are well positioned to provide the perspective required to foster the so-called 'mixed economy' of peer-led learning in a co-ordinated and consistent fashion.

\section{Conclusion}

This paper has presented a framework for the institutional management of peer-led learning that has emerged from the organic development of a range of initiatives over a number of years. This framework is holistic in the sense that it allows for the consideration of diverse iterations of peer-led learning across the entire institution without recourse to inflexible definitions or a uniformity of approach. The framework is based on an understanding of the diverse needs and perspectives of each subject area, alongside a broad interpretation of important transition points within each student's learning journey. A typology for peer-led learning has been developed to aid in understanding how these diverse approaches relate to one another, taking the degree of formality and the focus of each initiative as its basis. What has emerged is an institution-wide approach to peer-led learning that is scalable, sustainable and sensitive to the needs of students, disciplines and institutions alike.

\section{References}

Andreanoff, J. (2013) 'Supporting your peers: a pilot study of a robust peer mentoring scheme', Widening Participation and Lifelong Learning, 15(2), pp. 43-55.

Andrews, J. and Clark, R. (2011) Peer mentoring works! Birmingham: Aston University. Available at: https://www.heacademy.ac.uk/resources/detail/what-works-studentretention/Aston-What Works Final Reports-Dec 11 (Accessed: 14 November 2015). 
Ball, S. (2003) 'The teacher's soul and the terrors of performativity', Journal of Education Policy, 18(2), pp. 215-228.

Buckingham, L. and Newsham, I. (2012) 'Graphics guru and grasshopper scheme: the added value of Peer Learning', Gateway Papers: A Journal of Pedagogic Research in Education, Vol. 2, pp. 12-32.

Christie, H. (2014) 'Peer mentoring in higher education: issues of power and control', Teaching in Higher Education, 19(8), pp. 955-964.

Crisp, G. and Cruz, I. (2008) 'Mentoring college students: a critical review of the literature between 1990 and 2007', Research in Higher Education, 50(6), pp. 525-545.

Dawson, P., van der Meer, J., Skalicky, J. and Cowley, K. (2014) 'On the effectiveness of Supplemental Instruction: a systematic review of Supplemental Instruction and peer-assisted study sessions literature between 2001 and 2010', Review of Educational Research, 84(4), pp. 609-639.

Falchikov, N. (2001) Learning together: peer tutoring in higher education. Abingdon, Oxon: Routledge.

Fox, A. and Stevenson, L. (2006) 'Exploring the effectiveness of peer mentoring of accounting and finance students in higher education', Accounting Education, 15(2), pp. 189-202.

Gershenfeld, S. (2014) 'A review of undergraduate mentoring programs', Review of Educational Research, 20(10), pp. 1-27.

Gibson, F.M. and Myers, J. (2010) 'The fragmented route to a whole institution approach to integrating learning development. Reporting on a work in progress', Journal of Learning Development in Higher Education, Issue 2, February, pp. 1-10.

Hilsdon, J. (2013) 'Peer learning for change in higher education', Innovations in Education and Teaching International, 51(3), pp. 244-254. 
Jacobi, M. (1991) 'Mentoring and undergraduate academic success: a literature review', Review of Educational Research, 61(4), pp. 505-532.

Keenan, C. (2014) Mapping student-led peer learning in the UK. York: Higher Education Academy.

Kreber, C. (ed.) (2009) The university and its disciplines: teaching and learning within and beyond disciplinary boundaries. Abingdon, Oxon: Routledge.

Powis, C. (2010) 'We always come here': investigating the social in social learning', Enhancing the Learner Experience in Higher Education, 2(1), pp. 3-11.

Slavin-Baden, M., McFarland, L. and Slavin-Baden, J. (2008) 'Learning spaces, agency and notions of improvement: what influences thinking and practices about teaching and learning in higher education? An interpretive meta-ethnography', London Review of Education, 6(3), pp. 211-227.

Terrion, J.L. and Leonard, D. (2007) 'A taxonomy of the characteristics of student peer mentors in higher education: findings from a literature review', Mentoring \& Tutoring: Partnership in Learning, 15(2), pp. 149-164.

Topping, K. and Ehly, S. (eds.) (1998) Peer-assisted learning. Mahwah, New Jersey: Lawrence Erlbaum Associates.

\section{Author details}

Jason Eyre is a Senior Lecturer in Learning Development at De Montfort University Leicester, UK, and a Fellow of the Higher Education Academy. His interest in peer-led learning stems from a broader engagement with the idea of context in adult learning. He is currently completing a doctorate at the UCL Institute of Education examining the intersection between learners in higher education, the institution of the university, and the academic and professional disciplines. 